\title{
Studying feasibility of paste and thickened tailings at laboratory scale - pilot thickeners
}

\author{
A. Fernandez-Iglesias ArcelorMittal, Spain \\ A. Corrêa de Araujo ArcelorMittal, France \\ M. Goosens Independent Consultant, Brazil
}

\begin{abstract}
Thickening tailings until they reach a paste-consistency configuration is a process involving many factors. Lab scale work is required prior to studying the feasibility of paste thickening technologies for a given tailings. The global objective is to determine if a representative sample of non-thickened tailings can be engineered at laboratory scale to make paste; this work and its results will help determine the feasibility of the thickening process and the potential paste characteristics at industrial scale. This document aims to justify the need for this lab scale work and to provide information regarding lab scale paste thickeners by presenting the experiences obtained with an experimental lab-scale thickener.
\end{abstract}

Studying the feasibility of a paste and thickened tailings (P\&TT) alternative for a mine requires different types of laboratory and pilot scale tests. Many parameters and factors will affect the viability of these technologies for a given case. If we examine the most widely accepted theory, it seems that global design should flow 'upstream', starting from the storage area characteristics, stepping back to the piping requirements, and finally defining the thickening process to suit the required characteristics of the underflow.

The characteristics of tailings are probably the most important of the factors affecting the viability of the whole process. Location determines the climate, and especially the geological and mineralogical properties of the deposits, but tailings should not be considered as a natural material. They are a waste product of the mining process and are affected by several other parameters: the process used to separate the gangue from the ore, the chemicals added during these processes, the characteristics of the water used, etc. Even during the lifetime of a mine, the tailings characteristics may change due to evolution of the mineral grade and the associated beneficiation process.

All these arguments make tailings processing not only site dependant, but also time dependant. The design of a P\&TT process to thicken the waste of a mine requires a strong phase of prior research to determine its feasibility; not all tailings are amenable to being 'engineered' to reach paste consistency. Even if they are, there are several parameters that can be modified, such as additives, dosage, solids percentage, rheological properties, etc.

Thickener design should adapt to these requirements. However, few reference documents with procedures to design these pieces of equipment are available. It seems clear that producing paste at lab scale is imperative in order to have a first idea of how the tailings will behave after being thickened. In order to do this, having a bench scale thickener seems to be a good alternative. Static settling tests do not seem to resolve the need to determine underflow solid concentrations and overflow water characteristics. There is no reference bibliography to construct pilot units; in this study, an experimental column of $9 \mathrm{~cm}$ diameter is tested, operating in batch mode, providing a solid concentration for further tests. 


\section{Introduction}

Paste and thickened tailings (P\&TT) is an alternative for the treatment and disposal of mine waste. It consists of thickening the tailings (a mix of process water and waste solids obtained after the process of separating the gangue of an ore) to a higher solid content, recovering the water, and recycling it back to the process. The volume of the final waste, once it has been thickened, is smaller and requires less storage capacity. Thickening technologies applied to tailings, in order to reach solid concentrations over $50 \%$, are a real alternative to traditional disposal techniques.

The process of engineering the tailings until they reach a paste-consistency configuration is a process involving many factors. Rheology is always on the mind of high-density thickening process engineers, but before measuring the rheological characteristics, some other aspects must be studied. It seems clear that characterising the tailings feed material is a key task, as the behaviour of the thickened tailings will depend to some extent on those solids characteristics. In fact, not all the tailings can be engineered to make paste; water, additives, settling times, and thickening equipment can all be modified to some extent, but the original solid feed that has to be thickened cannot be changed.

Once the solid part of the tailing has been characterised, it should not be forgotten that most of the tailing is water. Chemistry of the liquid is important for the chemical aspects of the process but also from an environmental point of view. In the case presented here, the feed water was not problematic, but effluents from mining activities can be very different and complex. Heavy metal contents, high salinities, process additives dissolved, or extreme $\mathrm{pH}$ can all play an important role in the chemical behaviour of the thickening process and could affect the selection of the additives.

Flocculants are the chemical substances most widely used for the thickening processes, although coagulants can also be required. In the presented case, flocculant performance was already very effective in the settling process and coagulant dosage was not considered. Settling tests in cylinders are broadly used for the sizing of conventional thickening equipment. For high-density solid outputs, as obtained in highdensity or deep cone thickeners, there is not a widely accepted procedure for sizing; rules of thumb or correlations for similar previous designs are used. Each company that designs and manufactures thickeners can adjust the variables of diameter or bed height to achieve a given residence time for a required solid per cent output. The choice of these variables depends on their experience (Jewell and Fourie, 2006).

There are few references on how to tackle this design; however, as not all tailings are amenable to producing a paste consistency, it seems important to be able to achieve these characteristics under laboratory conditions, even when there are no clear calculations that lead to strong sizing parameters. Until considerably more is known about the operational principles of the thickener, it will remain important that laboratory tests be undertaken for any project planning to use ultra-high rate or ultra-high density (paste) thickeners.

\section{Methodology}

One of the main characteristics of P\&TT is high density. There is no clear consensus about the limits, but it is widely accepted that tailings with more than $50 \%$ solids belong to this category. However, there are some literature references (Newman et al., 2001) of tailings around $45 \%$ solids exhibiting paste properties (aluminium tailings or 'red mud') or even low solid contents, between 20 and $40 \%$ (in the case of chemically altered tailings from uranium and soda ash processing). But probably the main characteristic of P\&TT is the very low water bleed. This is usually linked to non-Newtonian behaviour, and this is why a yield-stress value is also often indicated as characteristic for classifying the thickened tailings.

In a more simplistic way, paste can be defined as a tailing which has been dewatered until it reaches a higher content of solids than of water, while maintaining a non-segregating behaviour. For a non-thickened tailing, if the solid characteristics are within a range of size and mineralogy, the process is usually carried out in a high-density or deep cone thickener with the aid of chemical substances as flocculants. To find out 
if a non-thickened tailing can be engineered to generate a paste with the above mentioned characteristics, these aspects should be studied:

- Solid characterisation.

- Water characterisation.

- Additive selection.

- Settling tests.

- Lab thickener test work.

- Rheology.

Of course, many other tests can be done to define critical aspects of the thickening process and, especially, to estimate the capital and operation costs. However, to determine if paste thickening is physically viable or not, determining the list of variables mentioned above could be enough.

\subsection{Solids characterisation}

There are references to the material properties that are likely to have an impact on the success and economic viability of a thickened or paste tailings system. The slurry density at which conventional tailings are pumped to the tailings storage facility is usually highly variable, but this variability does not commonly impact the operations in a significant way; however, it is recognised that it will affect the returning water flow.

Particle size distribution (PSD) or grain size distribution gives us an idea of the relative proportions of the particles in the sample according to their size. In many cases, tailings that are studied to be thickened to a high density have a very important proportion of fines. According to the Australian Centre for Geomechanics (Jewell and Fourie, 2006), complete reporting of material characteristics such as PSD should be encouraged in all reported studies. Mineralogy of the tailings using a technique such as X-ray diffraction, for example, is also useful, especially for clay-sized particles which are recognised to have the biggest interest for thickening applications, as well as $\mathrm{pH}$ and zeta potential.

\subsection{Water characterisation}

Water constitutes the higher percentage of the non-thickened tailings. When considering a tailings thickening process, water can be around $65-90 \%$ of the feed tailings. The characteristics of the water in the feed stream (before thickening) depend on many factors, such as the following:

- Available fresh water characteristics in the mine location. Some mines only have access to brackish waters or waters with high/low alkalinity levels. Fresh water in some world locations has particularly high levels of a given salt or metal.

- Beneficiation process used in the mine. Additives or reagents used during flotation may affect the composition of the water. $\mathrm{pH}$ changes may be desired or needed for a correct performance of the production process. Salts or polymeric substances are used for many extraction processes and are dissolved in the water.

- Characteristics of the solids in the tailings and their interaction with the water. Some sites face acid mine drainage issues due to the nature of the rocks. This lowers the $\mathrm{pH}$ of the water in contact with the solid, due to acid generating reactions, and may dissolve metals.

- Water recycling rate in the mine and water treatment existing before that water is recycled. If only clarification is implemented, suspended solids might have been removed to some extent, but other dissolved compounds are recycled back to the process, increasing the concentration of those compounds in the process. 
Water chemistry affects the performance of the additives. Not only will the solids characteristics influence their effectiveness, $\mathrm{pH}$, for example, will be decisive in the flocculant selection. Whatever the thickening equipment chosen, the process will generate a thickened tailings stream and a water stream. This water can be either recycled to the process or discharged as an effluent. Understanding the water feed is the first step to controlling the final water obtained in the overflow: its characteristics will depend mainly on the thickeners' performance (in terms of suspended solids content) and the additive's performance (if this affects the suspended solids to some extent). It is not only the characteristics of the particles (size, electric charge, etc.) that affect the flocculants performance, but also the water composition.

If the objective is recycling the water back to the process, there are parameters that should be controlled to avoid excessive concentration during successive recycling cycles. If the water is going to be discharged, the legal environmental restrictions must be kept in mind in choosing the additives or even considering further treatment of the water.

From the experimental point of view, performing different trials for all the tests requires a certain amount of water. When tailings are sampled, they usually have a higher solid content than the original tailings generated in the mine. Using distilled water, for example, may not give accurate results in terms of flocculant performance. Making 'synthetic water' as similar as possible to the original water is always recommended, especially when there are high concentrations of given compounds, such as salts.

\subsection{Additive selection}

The chemistry of the non-thickened tailings, mainly affected by the solid chemistry and the water characteristics, will define the requirements in terms of additive type and dosage. Most of the studies published about applications for paste thickening indicate the use of flocculants, but they do not so often indicate the use of coagulants. In the field of water treatment, coagulants are often added to modify the electronic charge around the particles; with this, it is possible to modify the zeta potential of the solution and make the floccule formation easier and faster.

Flocculants are polymeric substances broadly classified as cationic, anionic, or non-ionic, depending on their charge. The design of equipment for the thickening process should take into account the type of flocculant used, as this affects the density of the settling bed; solids that have been flocculated sediment at a much faster rate than solids that have not been flocculated. This has special importance also in terms of water treatment; the overflow of the thickener should have almost no presence of suspended solids.

\section{$2.4 \quad$ Settling tests}

There is a variety of thickeners, depending on the solid percentage that needs to be obtained in the underflow as well as the water characteristics of the overflow. A broad classification widely accepted includes clarifiers, conventional thickeners, high-rate thickeners, and ultra-high-rate thickeners.

The objective of clarifiers is to have a water overflow free of solids and therefore have no interest for real thickening applications; the objective is to have higher solids content in the tailings. However, there can be a polishing step for the overflow of other thickeners if the water quality is not as desired.

Conventional thickeners and high-rate thickeners are sized using the standard laboratory settling tests to determine the settling rate curve. This curve gives the maximum rate for the solids to settle (settling zone), the maximum settling rate achievable under given conditions. Unlike with paste thickeners, the hindered settling zone is large and cannot be neglected.

Ultra high-rate thickeners are sized by taking into account the settling rate of the material after flocculation: in this case, the hindered settling phase is considered small enough to not be taken into account. A rough idea of the final density that can be achieved in the underflow is given by the final concentration achieved in a static $1 \mathrm{~L}$ cylinder laboratory left for 24 hours settling time. In case the sample is small, this is an acceptable approximation. 


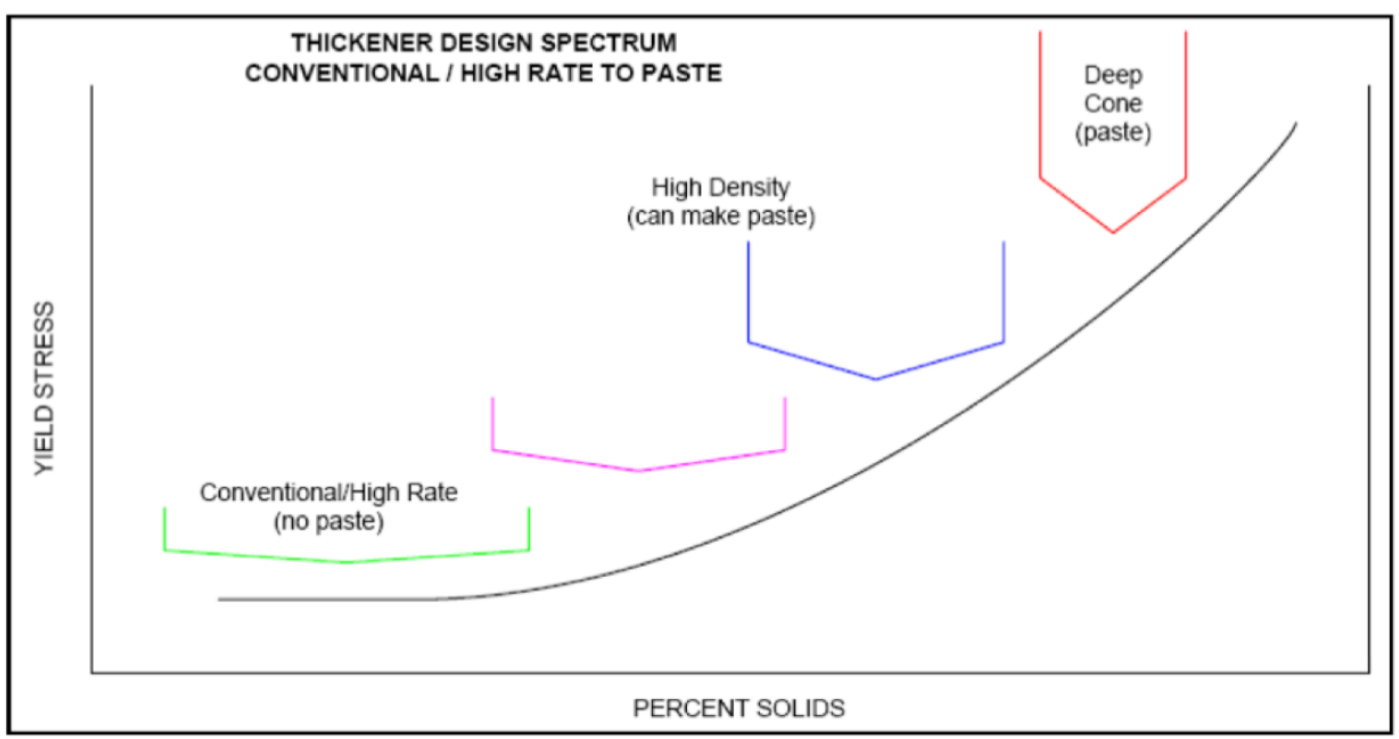

Figure 1 Thickener design spectrum (Gollaher et al., 2010)

Paste thickeners are also considered to have no hindered settling, so it can be assumed that for highdensity underflows, the settling process consists mainly of two phases or zones: free settling and constrained settling in the compression zone. However, conventional sizing calculations are not effective in sizing these units. The description of the thickening process for these thickener types is much less theoretical than for the previous types.

\subsection{Lab thickener test work}

Prediction of a thickener underflow density and the corresponding rheology at that density is typically done by referencing a database of previous test work conducted on slurries of very similar (or identical) metallurgical solids, particle size distribution, and flocculant dosages. The rheological data referenced should have information on the type of instrument used, the method applied, and the shear history of the sample (Jewell and Fourie, 2006). Obviously, this is an ideal situation, and this information is not always available or, if available, it is not always similar to the samples obtained during a pilot test campaign or existing tailing. There are metal mining activities that have been implementing paste technology for several years and have previous background and more references.

The settling tests can give a rough idea of the solids percentage that can be achieved in the underflow for conventional and ultra-high-rate thickeners. However, pilot paste thickeners are by far the best alternative for identifying the limits of the technology for a real tailings stream. There are few references for lab-scale pilot tests; some universities, but mainly commercial suppliers, use these column tests (Olcay Barreda et al., 2009; Bernal, 2010; Tao et al., 2008; Martin, 2012).

\section{$2.6 \quad$ Rheology}

The tailings are engineered to suit the disposal requirements, as opposed to engineering a facility for tailings storage (Sofrá and Boger, 2002). The design is generally understood as an 'upstream process', starting from the characteristics of the disposal area and studying the process back, in order to engineer a thickened tailing that suits that storage area at an optimum cost.

For P\&TT disposal, rheology must be well understood to ensure maximum efficiency of the entire disposal operation. Common rheological measurements are viscosity and yield stress; rheological studies give valuable information to define concentration for an optimum paste spreading degree, optimum conditions for pipeline transport, and feasibility of dewatering the tailings to the required solids content. 


\section{Experimental results}

The presented case refers to an iron mine that was studying a new beneficiation process. During a pilot test campaign for magnetic separation, around $200 \mathrm{~kg}$ of tailings below $150 \mathrm{~mm}$ were produced. The objective of the project was to determine the viability of those tailings for a P\&TT process, in order to reduce storage volume needs. So in this case, the goal was to determine if they could be engineered to reach paste consistency.

\subsection{Solids characterisation results}

The size distribution of the solid particles in the tailings is one of the key parameters for identifying the possibilities of reaching paste configuration. The following figures show the PSD in non-cumulative and cumulative graphs.
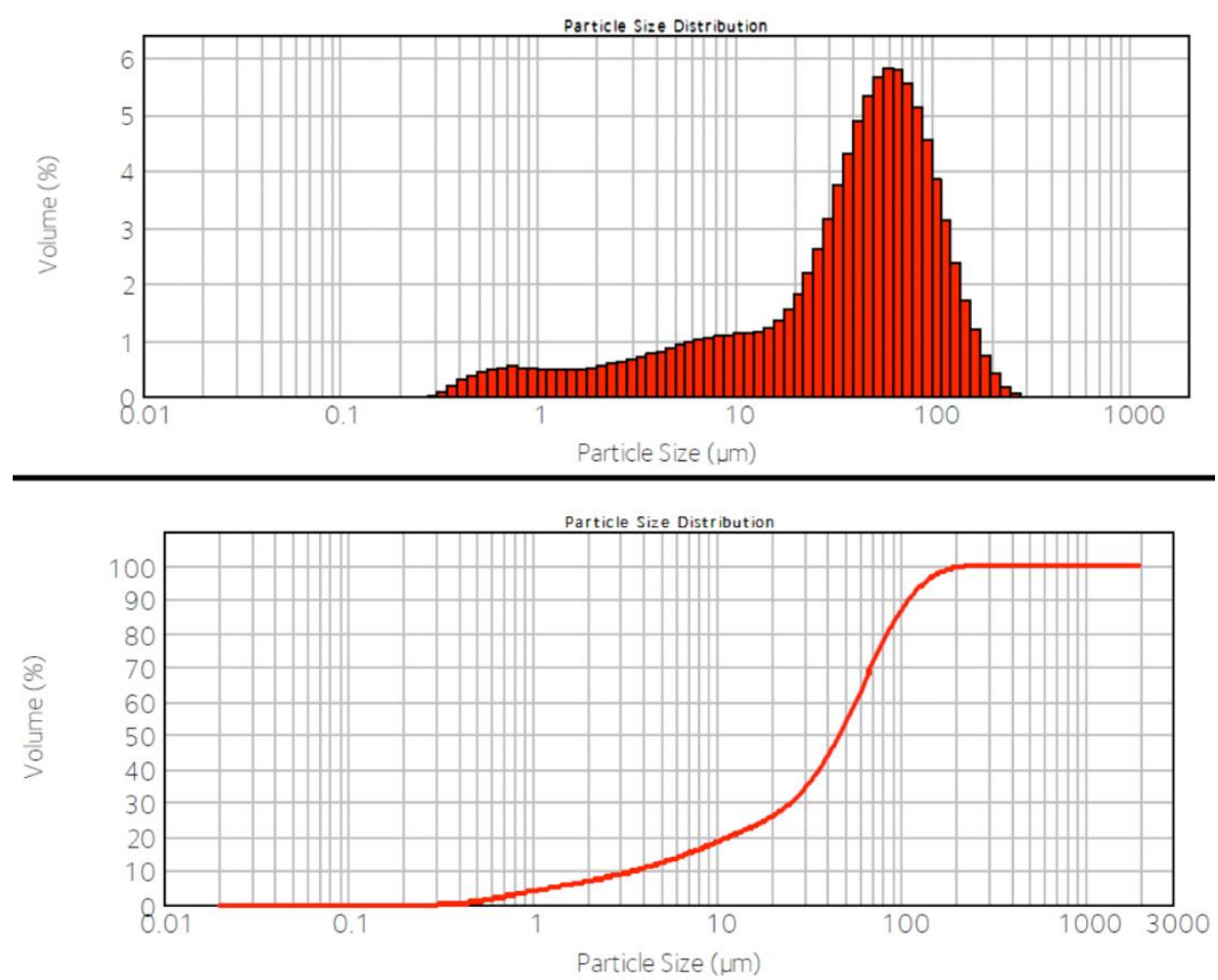

Figures 2 (a) and (b) Particle size distribution for the solids in the tailings

The $d_{50}$ value obtained was around $45 \mu \mathrm{m}$ and $d_{90}$ value around $100 \mu \mathrm{m}$. The ACG reported values of $d_{50}$ of tailings being deposited after thickening to a density as high as $85 \mu \mathrm{m}$. This could be a reference for the upper limit of the technology; in this case, the sample would be suitable for thickening. Clays, typically classified on a size basis as the fraction under $2 \mu \mathrm{m}$, were in this case a fraction below $5 \%$. It is recognised that the colloidal properties of clay suspensions are highly sensitive to chemical conditions, and their behaviour directly affects the operational performance of each aspect of the P\&TT process. In this case, the fraction is relatively low.

Parameters besides PSD were also studied, including density (helium picnometry), chemical composition by $\mathrm{X}$-ray fluorescence, wet chemical methods, and mineralogical composition by X-ray diffraction. The density obtained was $2.92 \mathrm{~g} / \mathrm{cm}^{3}$. The chemical composition included $\mathrm{Fe}, \mathrm{SiO}_{2}$ and $\mathrm{Al}_{2} \mathrm{O}_{3}$ as main compounds present. The size fraction, $<25 \mu \mathrm{m}$, was much richer in iron than the other size fractions, and consequently had less $\mathrm{SiO}_{2}$ than the other size fractions. The mineralogical characterisation was made based on X-ray diffraction (XRD) analysis and a scanning electronic microscope (SEM) campaign on one polished section. The analysed minerals, in descending order (semi-qualitative approach), were quartz, hematite, goethite, kaolinite and gibbsite. 
A detailed characterisation of the tailings is not always available, but PSD at least should be obtained in all cases: different authors agree in setting a size of $20 \mu \mathrm{m}$ as the limit for paste viability in case there is a range of $15-20 \%$ of particles passing that size. Some of the references talk about $15-20 \%$ by weight, but not all. The data show that $25.93 \%$ of particles are below a size of $20 \mu \mathrm{m}$, so there are $74.07 \%$ in volume of particles with a size bigger than $20 \mu \mathrm{m}$. The conclusion is that the sample fulfils that condition and is suitable for paste thickening.

\subsection{Water characterisation results}

As noted, the detailed characterisation is justified because of the importance of the feed water composition for the additive's performance, the final effluent that can be recycled or discharged, and the need to carrying out lab tests with the most realistic conditions. In this case, the water composition was not complex, with no important levels of any particular compound. Due to practical reasons, as explained in Section 2.2, the samples received had only a few litres, and it was recommended to produce synthetic water.

In the next table, the key water parameters from the original water (right column) and the water used for tests (left column) are shown. pH and conductivity should be as similar as possible. Calcium content and concentration of other ions should not have very different ranges. Total solids in the original sample are higher, but this should not be relevant as the water will be mixed with the tailings for the tests.

\section{Table 1 Relevant parameters in the original water and the water used for experimentation}

\begin{tabular}{lcc}
\hline & Water used for tests & Water from tailings sample \\
\hline $\mathrm{pH}$ & 7.4 & 7.4 \\
Conductivity $(\mu \mathrm{S} / \mathrm{cm})$ & 144 & 141 \\
Bicarbonates $\left(\mathrm{mg} / \mathrm{L} \mathrm{HCO}_{3}\right)$ & 12 & 23 \\
Colour & Imperceptible in $1 / 20$, & Imperceptible in $1 / 20$, \\
& $1 / 100$ dilution & $1 / 100$ dilution \\
Oils and greases $(\mathrm{mg} / \mathrm{L})$ & $<10$ & $<10$ \\
Total solids $(\mathrm{mg} / \mathrm{L})$ & 144 & 500 \\
Chlorides $(\mathrm{mg} / \mathrm{L})$ & 41.6 & $<3$ \\
Fluorides $(\mathrm{mg} / \mathrm{L})$ & 0.1 & $<0.1$ \\
Ca $(\mathrm{mg} / \mathrm{L})$ & 12.8 & 23.2 \\
Na $(\mathrm{mg} / \mathrm{L})$ & 15.2 & 2 \\
$\mathrm{~K}(\mathrm{mg} / \mathrm{L})$ & 0.7 & 5.2 \\
\hline
\end{tabular}

\subsection{Additives selection results}

Several samples of flocculants were available from different commercial suppliers. Powdered polymers were preferred, due to easier manipulation and accuracy for small quantities of flocculant prepared; emulsion flocculants are more difficult to measure. Identical solutions of $1 \mathrm{~g} / \mathrm{L}$ were prepared for each of the flocculants. For an initial screening, cylinder tests were carried out. Although flocculant screening is quite often done with a jar test, especially for water treatment, in this case it was interesting to observe the final height of the slurry in the cylinder. 


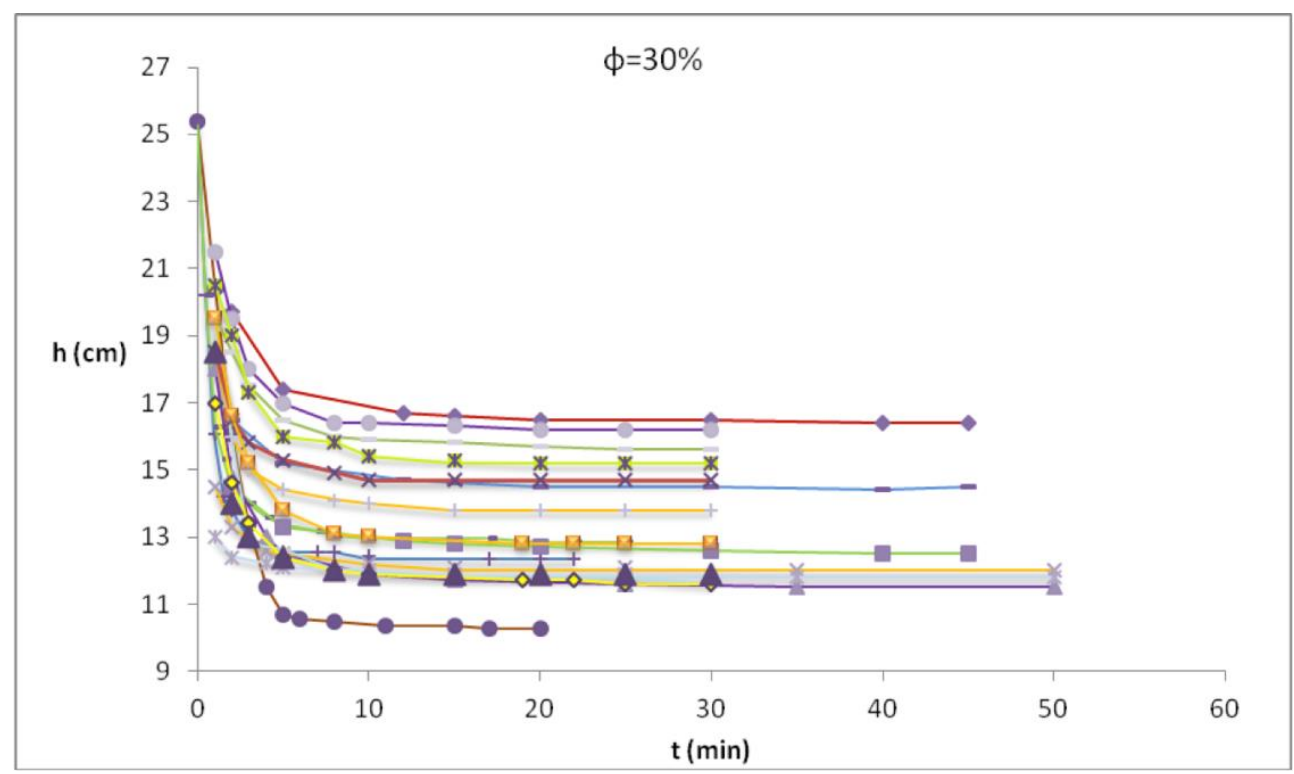

\section{Figure 3 Initial screening of flocculants for $30 \%$ solids feed}

Among the tested flocculants, there was not a clear correlation between the molecular weight of the product and the final compression achieved. Due to the chemistry of the slurry, few differences were found for cationic, anionic, or non-ionic flocculants. Some of the flocculants had a lower performance with turbidity in the overflow.

Finally, a commercial brand was chosen, and three different flocculants of similar charge (cationic, anionic and non-ionic) were used for the experiments, with the hope that there would be relevant differences observed in their behaviour. The next step was the flocculant dose screening, which showed that the smallest dose ( $5 \mathrm{~g} /$ ton) achieved almost zero turbidity in the overflow.

Solids percentage achieved after 24 hours were always lower for the anionic flocculant case. Cylinder tests used were $1,000 \mathrm{~mL}$. For cationic and non-ionic flocculants, the relation was not always the same: for some doses, higher solids percentages were reached for the cationic and in other cases the higher solid density was reached for the non-ionic.

The chemistry of the slurry with a quasi-neutral $\mathrm{pH}$ did not have a relevant effect in this case. Non-ionic flocculants are less affected by the presence of inorganic salts, but ionic flocculants can modify their coiling properties when these salts are dissolved.

In this case, the selection was the non-ionic flocculant; the performances of non-ionic and ionic flocculants were very similar. Choosing non-ionic reduces the risk of further modifications in the additive program due to changes in the salinity of the water (for example, potential changes in the layout of the water treatment during the life of the mine). In any case, if major changes take place, a review of the flocculant's performance should be considered. 


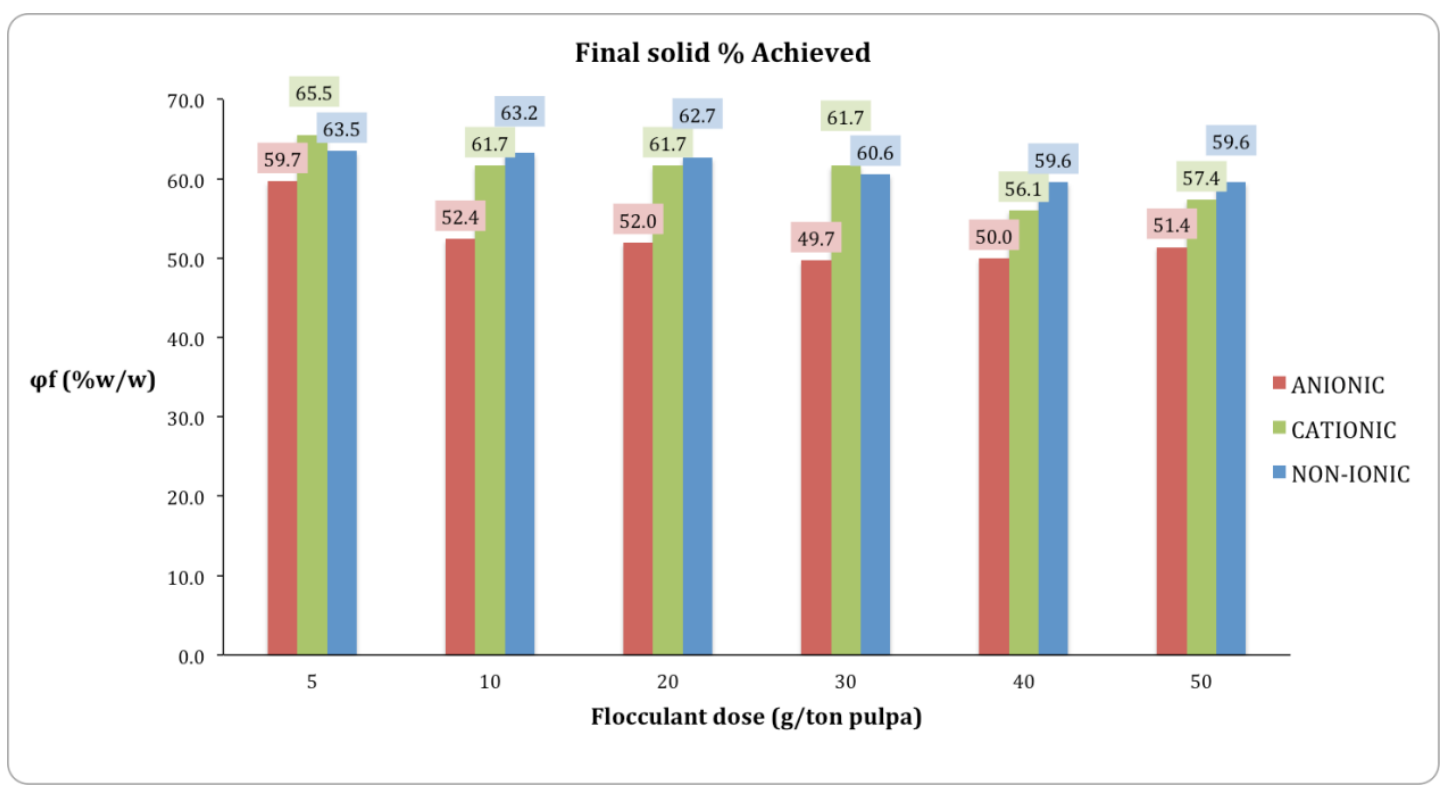

Figure 4 Final solids achieved in $1 \mathrm{~L}$ cylinders for different flocculant types and doses

Selection of the dose was based not only on the solids percentage achieved after 24 hours (as results were very similar) but mainly depended on the turbidity of the overflow during the initial minutes of the cylinder tests. The final selection of $20 \mathrm{~g} /$ ton was made on a semi-qualitative estimation: 5 and $10 \mathrm{~g} /$ ton presented turbidity during the first minutes, while $20 \mathrm{~g} /$ ton achieved a totally clear supernatant, as can be seen from the next figures. The photographs in Figures 6 through 11 were taken after approximately one minute of settling for the six tested dosages (above) and after 24 hours of settling time for the same experiments (below). Although the light and the angles do not allow an exact comparison of the experiments, the white background gives an idea of the turbidity of the water above the settling zone.

Settling velocities were very similar, as seen in the graph following the settling photographs. Five and $10 \mathrm{~g} /$ ton are slightly lower and do not have such a clear overflow. The final compression height represented is after only eight minutes; however the graph for 24 hours did not reflect any change in the order of the flocculants. 

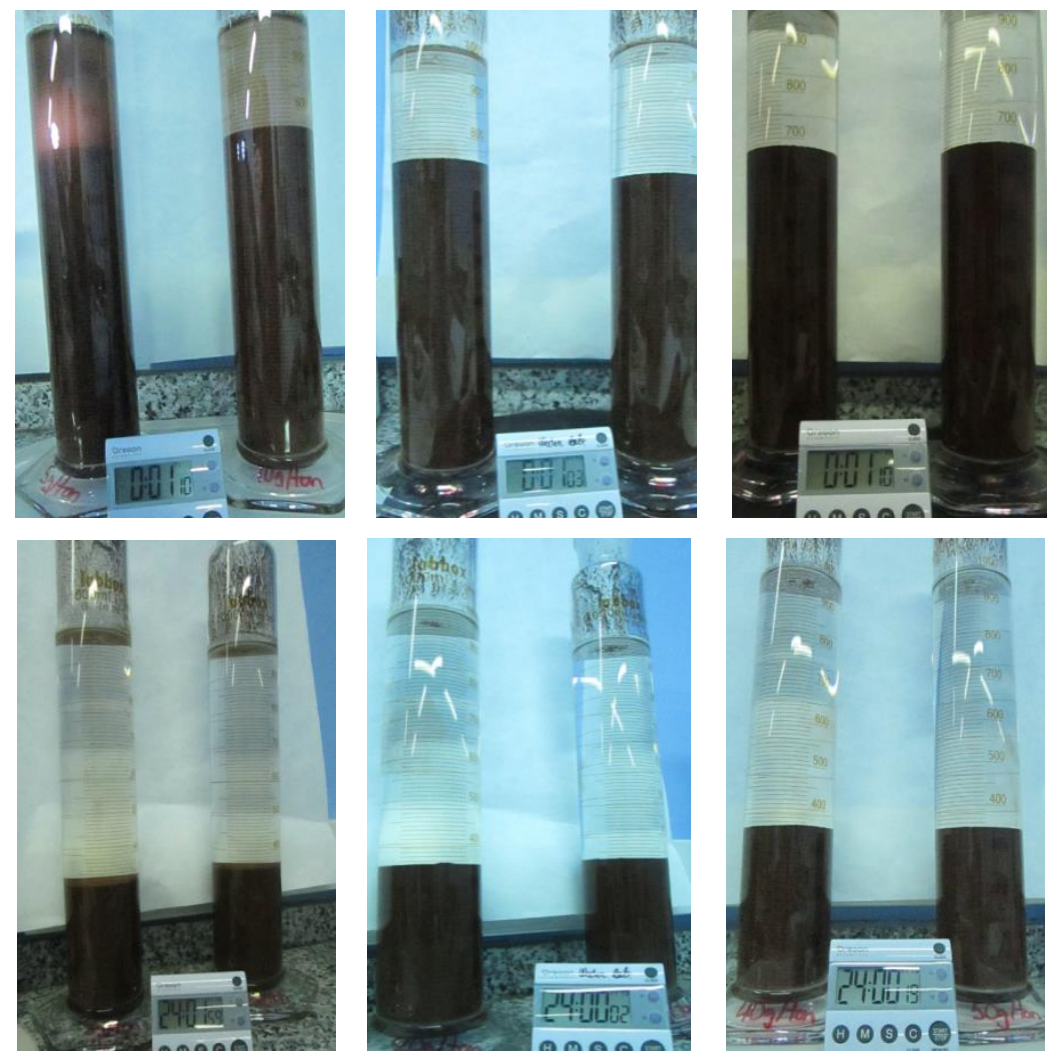

Figures 5- to $10 \quad 1,000 \mathrm{~mL}$ cylinder settling tests for $5,10,20,30,40 \% 50 \mathrm{~g} /$ ton after 1 min (above) and after $24 \mathrm{~h}$ (below)

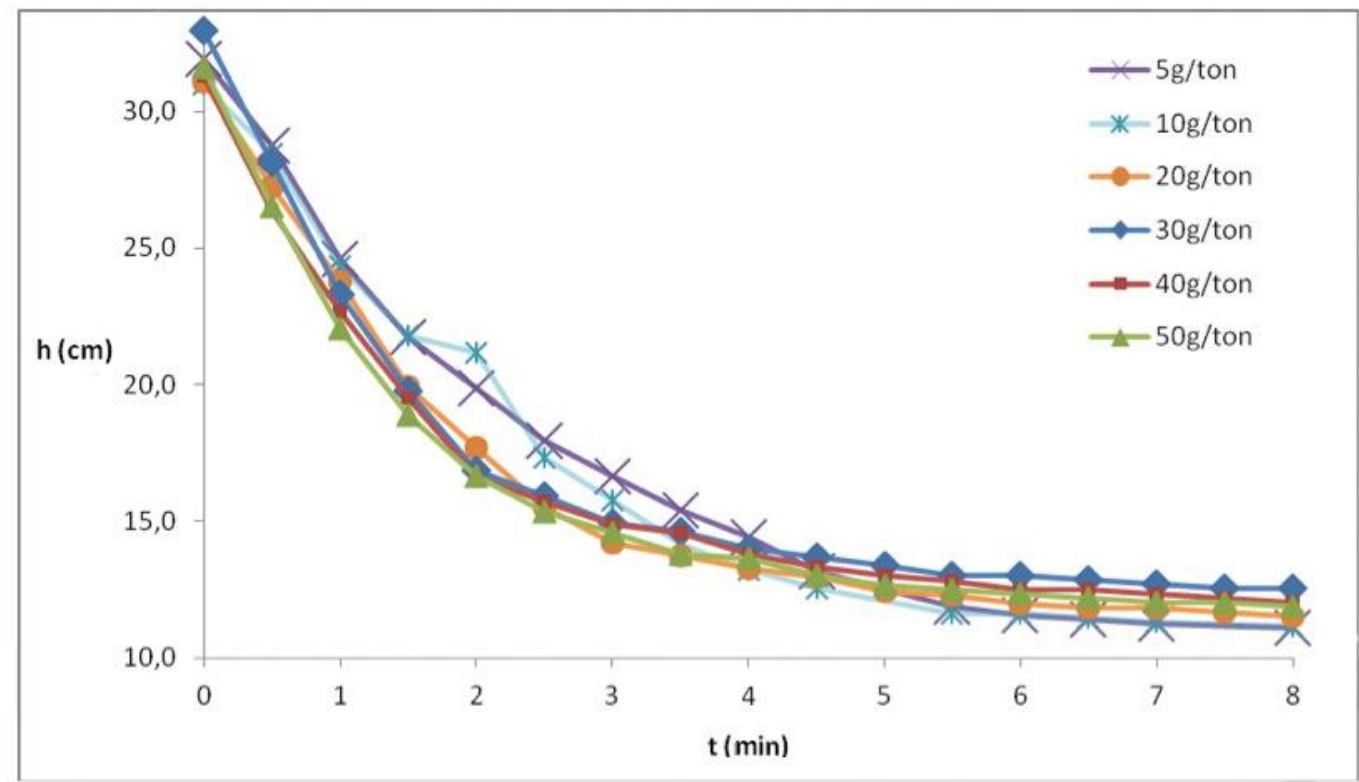

\section{Figure 11 Settling curves for the different doses}

\subsection{Settling tests results}

According to the explanation in the methodology section, there are established sizing procedures for clarifiers and conventional and high-rate thickeners. The hindered settling zone plays an important role in these cases. However, when sizing ultra-high rate and especially ultra-high-density and deep cone thickeners, the procedures are not so well established. In the case of ultra-high rate thickeners, the settling rate of the material after flocculation does not present a clear hindered phase but an idea of the final density that can be achieved in the underflow by the final concentration achieved in a static $1 \mathrm{~L}$ cylinder 
laboratory left for 24 hours of settling time. This estimation was done for three different tailings feeds: 20 , 30 , and $40 \%$ solids.

For this project, there was enough material to perform different tests, and so cylinder tests could be carried out with and without flocculation. Settling tests without flocculants would be used for conventional or highrate thickeners; although it was clear that the objective was not sizing one of these units, tests were made to compare with the flocculated ones.
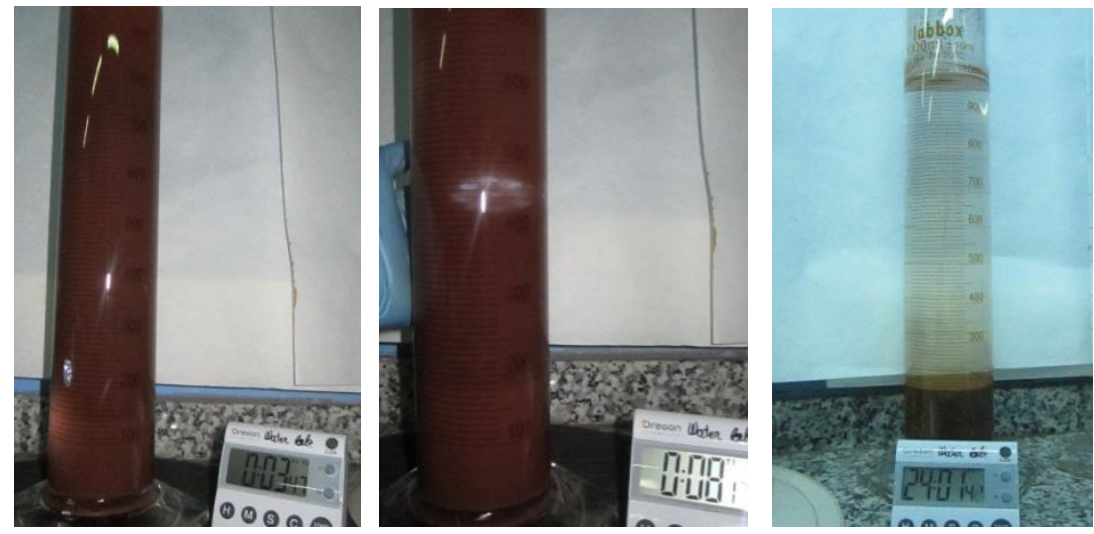

\section{Figures 12 to 14 Cylinder tests without flocculation (up to $24 \mathrm{~h}$ ) and $20 \%$ solids}
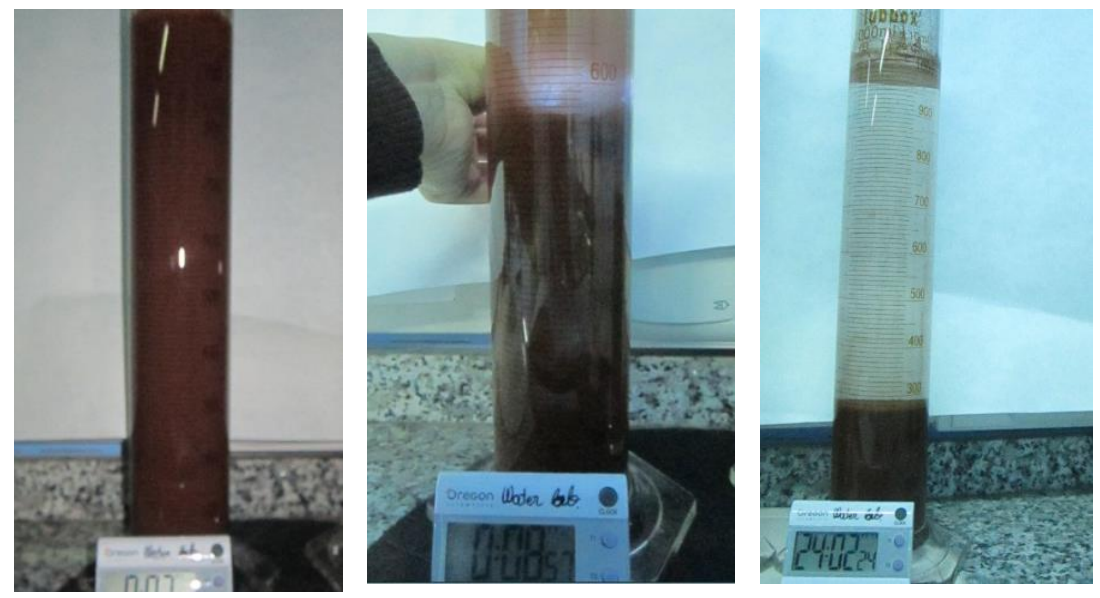

Figures 15 to 17 Cylinder tests without flocculation (up to $24 \mathrm{~h}$ ) and $30 \%$ solids
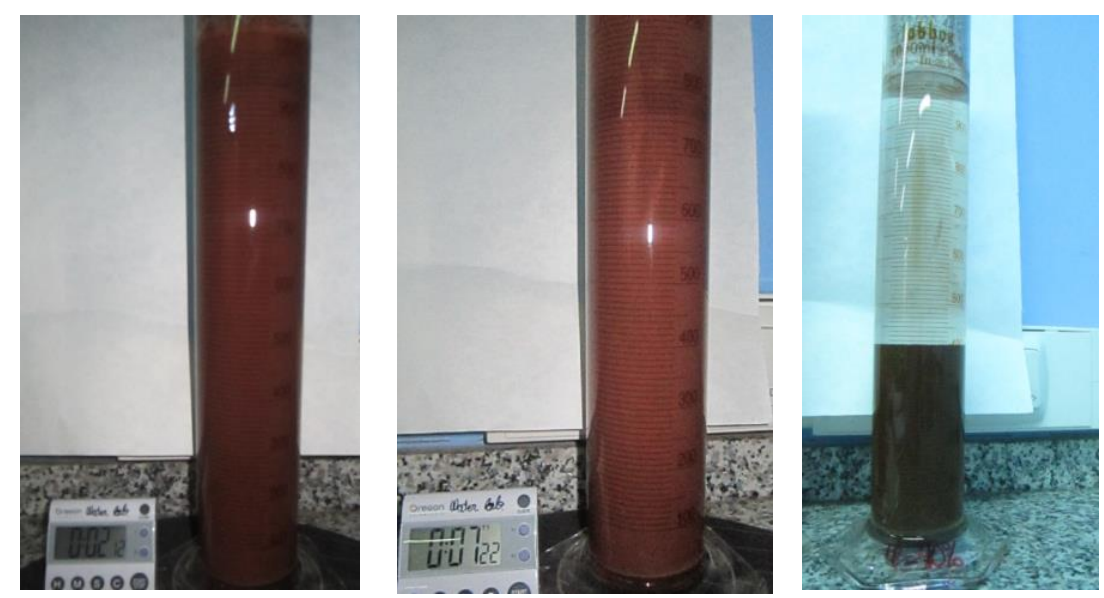

Figures 18 to 20 Cylinder tests without flocculation (up to $24 \mathrm{~h}$ ) and $40 \%$ solids 


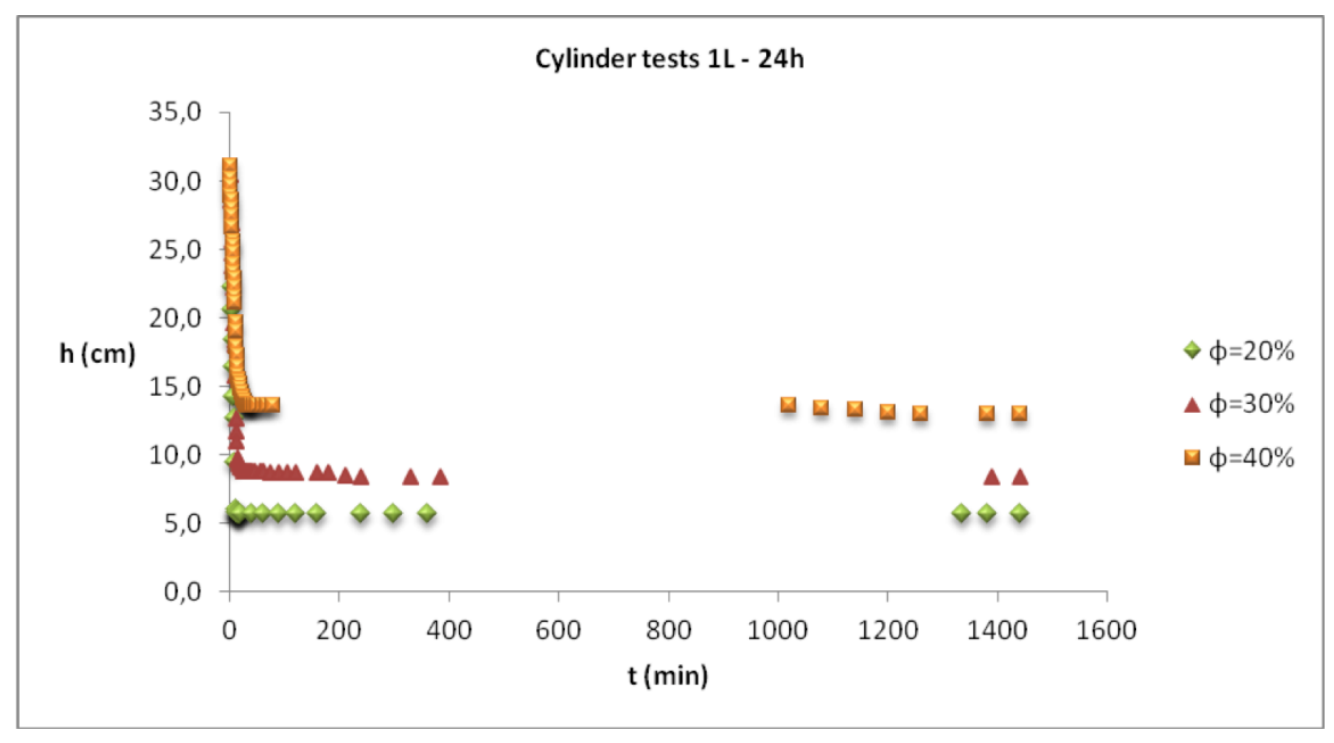

(a)

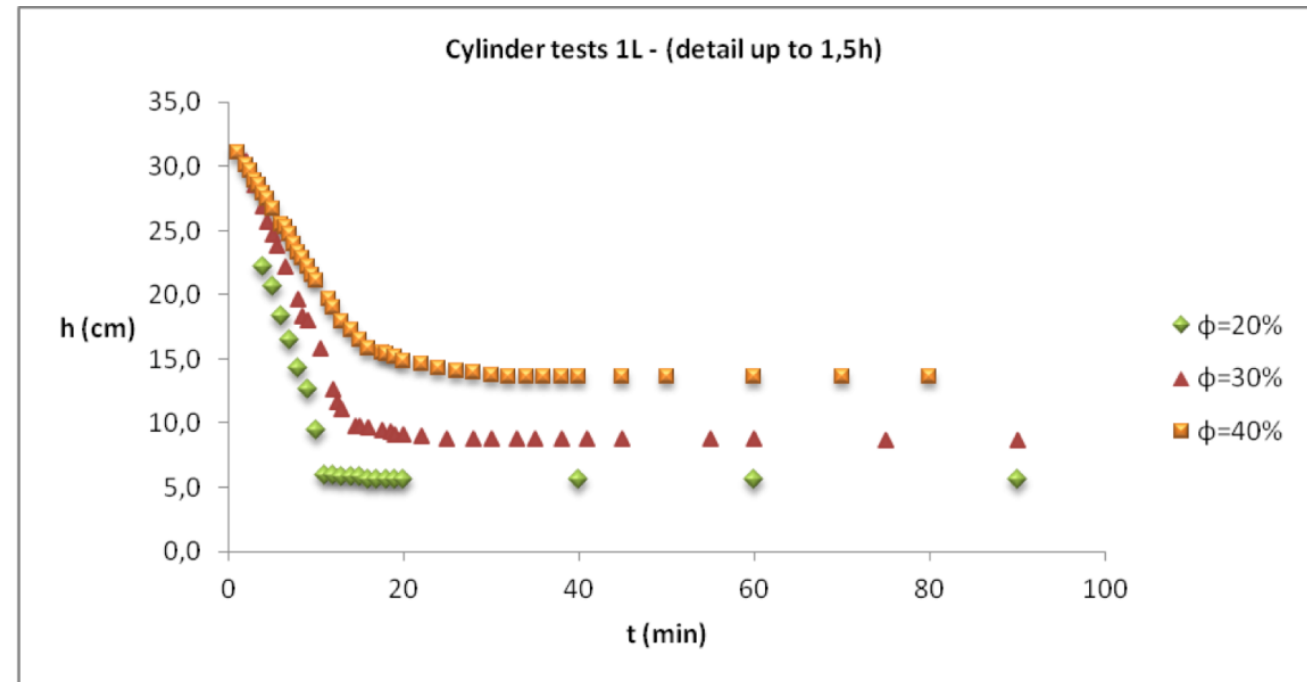

(b)

Figures 21 (a) and (b) Settling curves for different \% solids

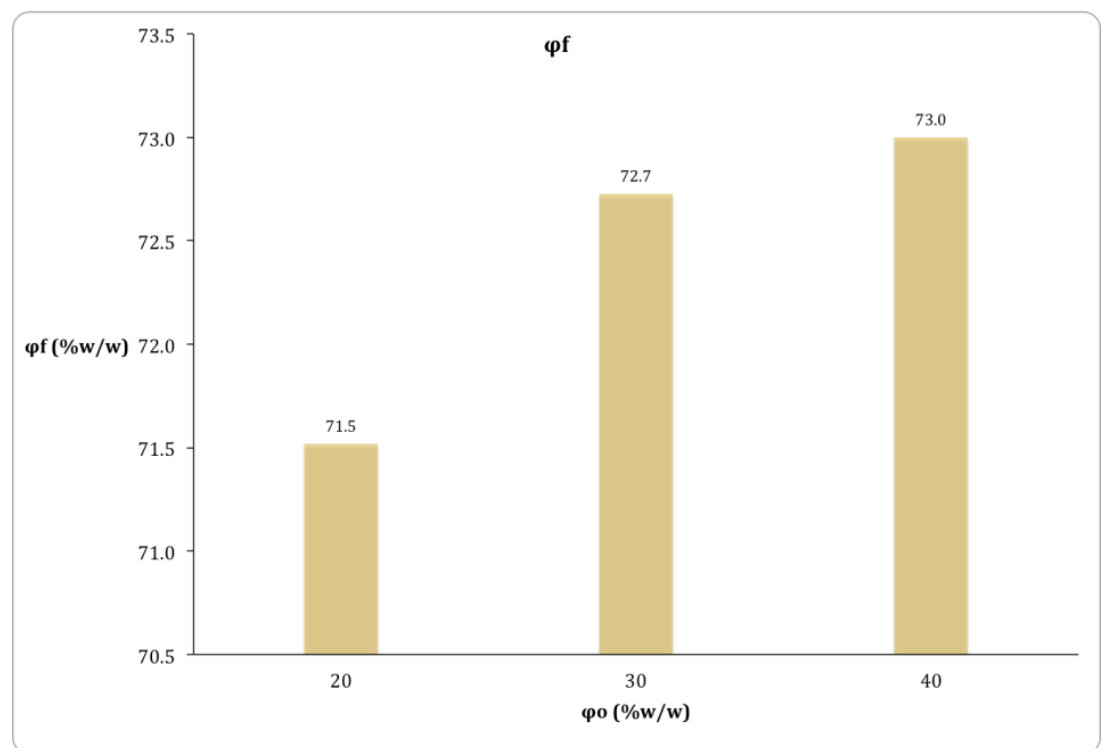

Figure 22 Final solid \% estimation for different feeds after $24 \mathrm{~h}$ without flocculation 


\subsection{Lab thickener test work results}

An experimental pilot column was used for performing batch tests at lab scale. The continuous stirred column is $9 \mathrm{~cm}$ diameter and has two modules of around 35 and $60 \mathrm{~cm}$ that can be used together for a higher bed height. In this case, the $35 \mathrm{~cm}$ column module was used, with a total volume of around $3 \mathrm{~L}$. The column was charged with a $30 \%$ tailings feed and the selected dose of $20 \mathrm{~g} /$ ton. Stirring was constant at $4 \mathrm{rpm}$. After approximately 10 minutes, the bed height was stable. Three trials were performed, sampling underflow every hour. After 2 hours, solids per cent obtained were 67.6, 63.5 and 65.3\%.
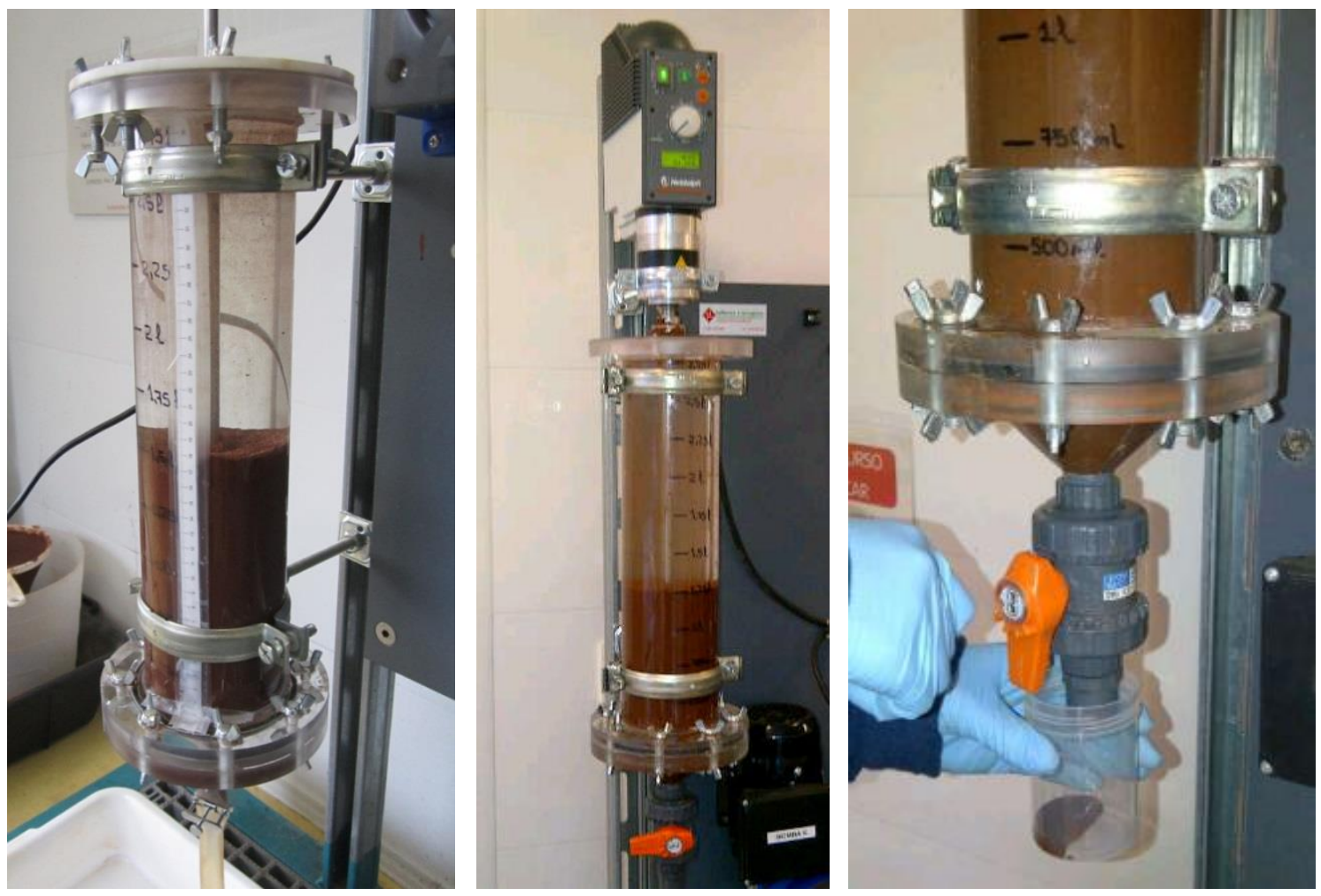

Figures 23 Lab thickener tests

\subsection{Rheology results}

Rheological studies should always reference the equipment used; for this project, a Brookfield viscometer DVIII-Ultra was used. Yield stress was measured for $65 \%$ tailings, obtaining the following graph. 


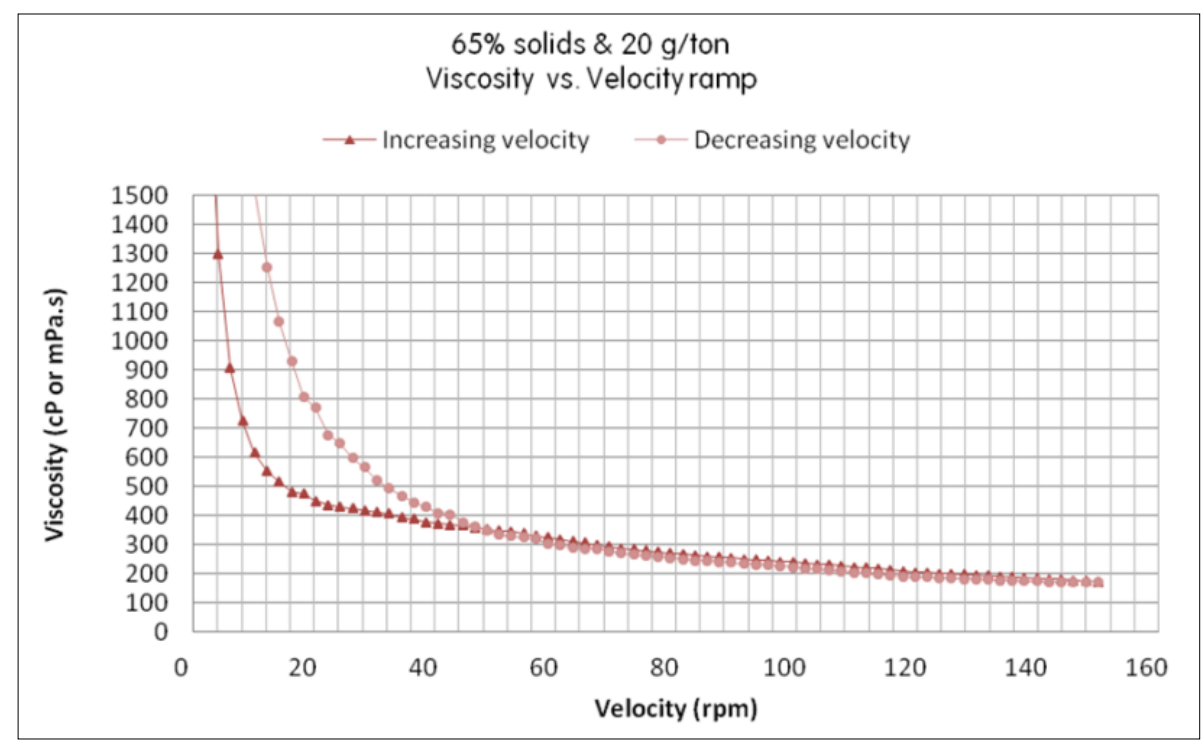

\section{Figure 24 Viscosity versus $\mathrm{rpm}$ for a sample of $65 \%$ solids and $20 \mathrm{~g} / \mathrm{ton}$}

A viscosity versus velocity test for $65 \%$ and $20 \mathrm{~g} /$ ton flocculant shows that the viscosity of the tailings decreases when the velocity is increased. This confirms non-Newtonian fluid behaviour with viscosity decreasing as rpm increase. Viscosity tends to a stable value of around $173 \mathrm{cP}$. At lower velocities (left part of the graphic), hysteresis phenomenon is observed: for the same rpm value, the viscosity increases with time; the sample is more viscous in the ramp back.

Similar tests were performed for manually prepared samples with higher solid contents, obtaining similar behaviours but higher viscosity values. A sheared yield-stress of $15.03 \mathrm{~Pa}$ was obtained. As the result was lower than expected, several measurements were made for higher solid concentrations, with all the results aligned. A 77\% solids sample was prepared manually, obtaining values around $60 \mathrm{~Pa}$ maximum. Some references have also reported low yield-stress values (Vietti et al., 2011; Paterson, 2004; Clayton et al., 2003; Jewell and Fourie, 2006). References for iron tailings are scarce, but some of them have also reported low yield-stress values for solid contents below 66\% solids (C. de Araujo et al., 2006; Slotte et al., 2005; Morais, 2011). Further testing for manually prepared samples with higher solid \% indicated a consistency in the results. 


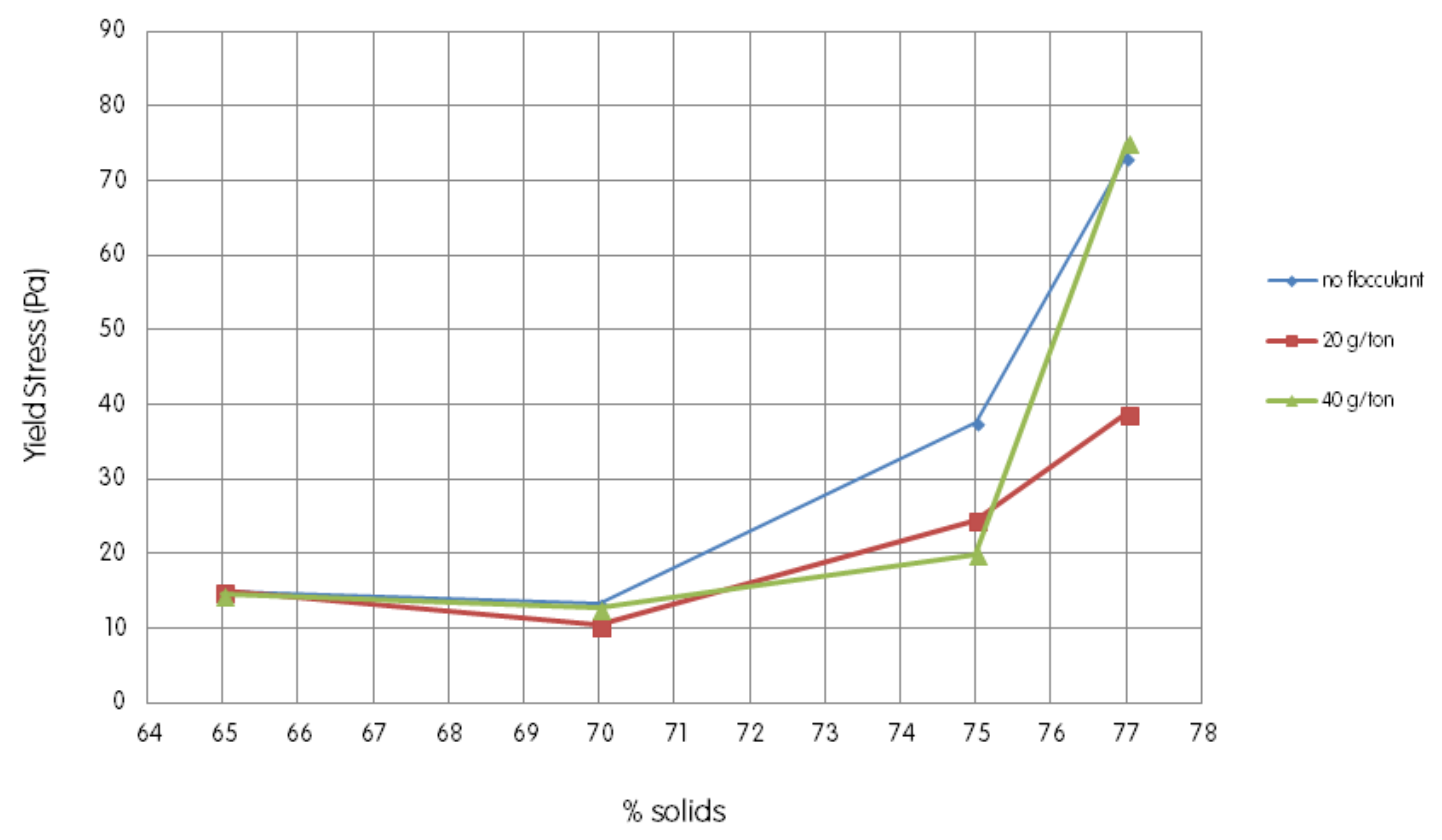

Figure 25 Yield stress measurements for no flocculated samples, 20 and $40 \mathrm{~g} / \mathrm{ton}$

\section{Conclusions}

The process of engineering the tailings until they reach a paste consistency is affected by many factors. Prediction of a paste thickener underflow cannot be done theoretically; having a database of previous similar cases is the preferred methodology. Until considerably more is known about the operational principles of the thickener, it will remain important that laboratory tests be undertaken for any project planning to use ultra-high rate or ultra-high density (paste) thickeners.

Some of the laboratory tests that can be carried out to properly characterise these databases include solid and water characterisation, additive selection, settling tests under different conditions, lab thickener test work, and rheology. In this case, these parameters were studied for a sample of iron ore tailings obtained after a pilot test. The main objective was to determine if the tailings sample received could be engineered to achieve paste consistency. The solid concentrations achieved were high, but the rheological characterisation indicated that yield-stress values were low if compared with other pastes. The references for iron ore P\&TT applications are not as extensive as for other metal mining activities; sharing the experiences for the lab and pilot tests of current and future campaigns would be desirable. Adding binders such as cement has been pointed out as an option for achieving stack deposition of tailings with these characteristic.

The settling tests can give a rough idea of the solids percentage that can be achieved in the underflow for conventional and ultra-high rate thickeners. However, pilot paste thickeners are by far the best alternative for identifying the limits of the technology for a real tailings stream. There are few references for lab-scale pilot tests. Experimental equipment was built for this project, opening the door for designing future tests and obtaining correlations after adjusting different variables (bed height, residence time, stirring velocities, stirrer characteristics, discharge cone geometry, additive dosage, addition of binders, etc.) and assuring a proper rheological characterisation.

\section{References}

Bernal, L. (2010) Implementación del sistema de relaves espesados en Minera Esperanza, Seminar RELPAS 2010, November 2010 Chile Presentation 1 in Module One, http://www.relpas.cl/neo_2011/interior_8.php.

C. de Araujo, A., Sales Valadão, G.E., Cordeiro, R. and Hernández, C.A. (2006) Efecto de ligantes en la consistencia de una pasta mineral, VIII Jornadas Argentinas de Tratamiento de Minerales, San Juan, Argentina. 
Clayton, S., Grice, T.G. and Boger, D.V. (2003) Analysis of the slump test for on-site yield stress measurement of mineral suspensions, International Journal of Mineral Processing, Vol. 70, pp. 3-21.

Gollaher, T., Johnson, J.L., Biesinger, M.T. and Accioly, A.H.L. (2010) Paste thickening tailings: Recent examples of a rapidly emerging technology, SME Annual Meeting.

Jewell, R.J. and Fourie, A.B. (2006) Paste and Thickened Tailings - A Guide, 2nd edition, Australian Centre for Geomechanics, Perth, $242 \mathrm{p}$.

Martin, T. (2012) Tailings testing for design, EduMine Tailings 101 WebCast.

Morais, A.F. (2011) Espessamento e transporte de pasta mineral, Departamento de Engenharia de Minas, Universidade Federal de Minas Gerais.

Newman, P., White, R. and Cadden, A. (2001) Paste - The future of tailings disposal? In Proceedings 2nd International Conference on Mining and the Environment, Skelleftea, Sweden, pp. 594-603.

Olcay Barreda, R.H., Correa, A., Sales Valadão, G.E. and Hernández, Osorio C. (2009) Development and testing of a laboratory scale paste thickener, in Proceedings 12th International Seminar on Paste and Thickened Tailings (Paste09), R.J. Jewell, A.B. Fourie, S. Barrera, J. Wiertz (eds), 21-24 April 2009, Viña Del Mar, Chile, Gecamin Limited, Santiago, Australian Centre for Geomechanics, Perth, pp. 119-128.

Paterson, A.J.C. (2004) High density and paste tailings transport systems, in Proceedings International Platinum Conference 'Platinum Adding Value', The South African Institute for Mining and Metallurgy, Johannesburg.

Slotte, S., Johnson, J. and Crozier, M. (2005) Paste thickening iron ore tailings, in Proceedings XXXV Ironmaking and Raw Materials Seminar, VI Brazilian Symposium on Iron Ore, 30 August to 2 September, Florianópolis, Santa Catarina, Brazil.

Sofrá, F. and Boger, D.V. (2002) Environmental rheology for waste minimisation in the minerals industry, Chemical Engineering Journal, Vol. 86, pp. 319-330.

Tao, D., Parekh, B.K. and Honaker, R. (2008) Development and pilot-scale demonstration of deep cone paste thickening process for phosphatic clay disposal: Final report, FIPR Publication No. 02-162-229, Florida Industrial and Phosphate Research Institute

Vietti, A.J., Boshoff, J.C.J. and Cope, A. (2011) Does thickening save water? The Journal of the Southern African Institute of Mining and Metallurgy, Vol. 111, pp. 63-66. 